\title{
Introduction to the Special Issue of the Journal of Agricultural and Environmental Ethics from EURSAFE 2010
}

\author{
Leire Escajedo San-Epifanio • Mickey Gjerris
}

Accepted: 3 March 2012/ Published online: 23 March 2012

(C) Springer Science+Business Media B.V. 2012

The Rome Declaration on World Food Security (1996) states that "food security exists when all people, at all times, have physical and economic access to sufficient, safe and nutritious food to meet their dietary needs and food preferences for an active and healthy life." 1 out of every 6 inhabitants of the planet-more than 1 billion-is in a situation of food insecurity, which means that there is no guaranteed access to food (FAO 2010). The problem is, by all measures, a very serious one.

The 9th EurSafe Congress was held in Bilbao in October 2010, under the motto "Global Food Security: Ethical and Legal Challenges." The objective was to address the ethical dimensions of food security and insecurity; that is, both reflect upon the challenges and the strategies aimed at ensuring the human right to food, and undertake a critical analysis of the attitudes and actions currently blocking progress towards the goal of global food security. What are the individual, collective, and institutional solutions being developed in favor of global food security? And what, on the other hand, are those attitudes and actions which make this goal increasingly distant?

Very closely connected to both questions is the issue of the factors or causes to which we attribute food insecurity and its increase in recent decades. What are the economical and political factors, both national and international behind this? And is it perhaps also related to the accumulated effect of certain patterns of consumption? What are the factors and how should they be acted upon? Seeking answers to these questions leads to intense debates over the degree to which science and technology

\footnotetext{
L. Escajedo San-Epifanio ( $₫$ )

Department of Constitutional Law and History of Political Thought, Faculty of Social Sciences and Communication, University of the Basque Country, Bilbao, Spain e-mail: leire.escajedo@ehu.es
}

\section{Gjerris}

Faculty of Science, Institute of Food and Resource Economics, University of Copenhagen,

Copenhagen, Denmark

e-mail: Mgj@foi.ku.dk 
can contribute towards attaining the Millennium Development Goals, how to understand the concept of sustainability, problems and advantages of different farming methods, new proposals for empowering food consumers, and discussions of the usefulness of the concept of the political consumer.

More than 150 experts from 23 countries and a wide range of academic disciplines took part in the EURSAFE 2010, and offered ethical reflections on the subject enriched by contributions from Biological Science and Biomedicine, Veterinary Science, Food Science and Technology, Nutrition and Bromatology, Humanities, and Social and Legal Science. Preceded by other EurSafe conferences in Nottingham (2009), Vienna (2007), Oslo (2006), Leuven (2004), Toulouse (2003), Florence (2001), Copenhagen (2000), and Wageningen (1999), EurSafe 2012 was organized by the Inter-University Chair in Law and the Human Genome (University of Deusto and University of the Basque Country).

More than 70 manuscripts presented at the Congress were included in the volume Global food security: Ethical and Legal Challenges (eds.: C. Romeo Casabona, L. Escajedo San Epifanio, A. Emaldi Cirón), edited by Wageningen Academics Publishers. This Special Issue of the Journal of Agricultural and Environmental Ethics is the result of an invitation extended to selected authors from that volume to further develop their research and produce an extended and more complete version of their research. In addition, this issue aims to serve as an example of the variety of topics that, within the topic of Global Food Security, were the subject of detailed analysis at the Bilbao Congress.

Reflections on the factors that cause food insecurity and the possible paths to solution generally reveal conflicts of values and of ethical norms. Not only is it difficult to take every value into account, but neither is it possible to find (or at least agree upon) theory-neutral standpoints from which to address these reflections. Far from shrinking away from these ethical disagreements, the goal of this issue is to bring these dimensions to the surface and encourage both an academic debate and greater deliberation on the part of institutions and citizens. It is thus the joint goal of the papers presented here, each one within its specific subject matter, to inspire to disagreement, reflection, and enlightened debate on the subject of global food security.

Entitled Shifting Schemes of naturalness, the text by P. F. Van Haperen, B. Gremmen, and J. Jacobs focuses upon the effect of the concept of naturalness on modern (agro) biotechnology. The concept is, the article argues, employed with different functions and connotations depending on the context and, on occasions, it hinders a more open discussion, a more productive debate regarding the set of issues and the specific applications and development of this technology.

From the University of Alaska Anchorage, Raymond Anthony, meanwhile, presents the results of his research under the title Taming the Unruly side of Ethics: overcoming challenges of bottom-up approach to ethics in the areas of climate change and food security. It is based on a reading of that which, in the Alaskan model, precludes a deliberative atmosphere and a setting in which experts, policy makers, and laypersons might interact and address ethical concerns in an efficient manner. He analyses the elements that provoke unruliness, those disruptive mechanisms that can prevent ethical issues from being adequately addressed in policy-making. 
Next is a couple of articles focusing on aquaculture. And in particular, proposals aimed at satisfying a growing demand for fish with the decline in wild fish populations. In a scenario in which the sector has expanded considerably, the first paper considers the absence of a regulatory framework for aquaculture. The title is Moral Status of the African Catfish, written by B. Bovenkerk and F. Meijboom, of Utrecht University. From how fish should be treated, to questions of profitability, sustainability, or consumer awareness, there is a wide range of issues in need of a regulatory framework. With the aim of helping to define these frameworks, the authors analyze how the different moral consideration of the animal, in this case of the fish used in aquaculture, impacts upon the answer to other questions with regard to regulation. They highlight the absence of a theory-neutral standpoint and its consequences, as one of the challenges to overcome in the clarification of proposals for the regulation of aquaculture.

The second paper on aquaculture addresses the issue of GM fish in a plural context. L. Coutellec and I. Doussan present their Attempt to typologise relations between different words (human, animal, living) based on legal and ethical questions surrounding the status of GM fish. Taking as starting point GM fish as relational-objects, they proceed to approach the latter within the complexity of different relations; relations between human beings and also how human beings relate with life and other living creatures. In a plural scenario, in which these relations are not only alive, but also interact, this constitutes quite a challenge when it comes to configuring legal frameworks that are structured and coherent with pluralism.

Leaving aquaculture the articles now turn to the issue of Ethics and Consumption. This was an important issue at the Bilbao Conference. Access to the necessary food to meet people's dietary needs and the challenge of accommodating different food preferences were issues that were covered. In addition to these, the Conference addressed those proposals or strategies for improving food systems centered upon the consumer. Taking action in patterns of consumption, or generating in consumers a feeling of responsibility for their food options are some of the key points of these proposals.

In this area two articles have been written for this special issue. The first of them, by De Bakker and H. Dagevos, is entitled Reducing meat consumption: ethical arguments in the context of today's consumer society. Secondly, J. De Tavernier's work, Food Citizenship: is there a duty of responsible consumption? The possibilities of persuasion in order to modify current patterns of meat consumption in the society of today provide the background for the first analysis, which presents as obstacles to be surmounted the moral ambivalence and complexity of our contemporary societies. De Tavernier, meanwhile, explores the consideration of food consumption as the expression of a kind of citizenship and the relevance vis-à-vis consumer autonomy of the development of food labeling providing information about anything that may be relevant when making decisions with regard to responsible consumption.

The possible collision between bioenergies and the objectives of food security constituted two more important issues at the conference. C. Gamborg, K. Millar, and P. Sandøe, in their work Bioenergy and agricultural land use: examining the 
framing of the ethical debate, address ethical issues related with bioenergies in two senses. On the one hand, whether it is unfair to use land for bioenergíes during times of food insecurity and significant food poverty; and, on the other hand, although from a perspective closely linked to the aforementioned issue, the effects of bioenergies upon biodiversity. Within their reflection they consider, amongst others, the consequences of current legal mechanisms; in other words, whether they make a positive contribution or, to the contrary, exacerbate some of the problems that already exist, benefiting some actors to the detriment of others and sometimes acting as barriers that prevent the defense of certain values and collectives.

It is the hope of the guest editors of this special issue of the Journal on Agricultural and Environmental Ethics that the articles presented here will show the variety of issues related to the challenge of Global Food Security, but also make apparent how these issues are interrelated. The solutions cannot be found as isolated bits of technical improvement within disparate sectors of agriculture and environmental planning. It is not only technology that is called for when challenged with ensuring food for the human inhabitants of our planet. A deeper understanding of the ethical issues and an understanding of the interrelatedness of problems, challenges, and solutions is necessary to address the issue in an adequate way. 